\title{
Üniversite Öğrencilerinde Cep Telefonlarının Problemli Kullanımı İle Serbest Zaman Tatmini İlişkisinin İncelenmesi
}

\author{
Examination of The Relationship Between Problematic Use of Mobile Phones and Leisure \\ Satisfaction in University Students
}

\author{
Gökçen AKYÜREK ${ }^{1}$, Sinem KARS ${ }^{2}$, Gonca BUMIN ${ }^{3}$ \\ ${ }^{1}$ Dr. Fzt., Hacettepe Üniversitesi, Sağlık Bilimleri Fakültesi, Ergoterapi Bölümü, Ankara \\ ${ }^{2}$ Erg., Hacettepe Üniversitesi, Sağlık Bilimleri Fakültesi, Ergoterapi Bölümü, Ankara \\ ${ }^{3}$ Prof. Dr., Hacettepe Üniversitesi, Sağlık Bilimleri Fakültesi, Ergoterapi Bölümü, Ankara
}

\section{öz}

\begin{abstract}
Amaç: Bu çalışmanın amacı üniversite öğrencilerinin cep telefonu kullanımının serbest zaman aktiviteleri memnuniyeti ile ilişkisini incelemektir. Gereç ve Yöntem: Ergoterapi Bölümünde okuyan, çalışmaya katılmaya gönüllü olan 132 öğrenci (yaş ortalaması 20,7 $\pm 2,47$; \%47,3'ü erkekti) çalışmaya alınmıştır. Çalışmada Serbest Zaman Değerlendirme Anketi ve Cep Telefonu Problemli Kullanım Ölçeği kullanıldı. Sonuçlar: Cep Telefonu Problemli Kullanım Ölçeğinin toplam puanı, bağımsızlık ve sosyal ilişki alt ölçeği ile Serbest Zaman Değerlendirme Anketinin eğitim ve gevşeme alt ölçekleri arasında $(p<0,001)$ ve Cep Telefonu Problemli Kullanım Ölçeğinin sosyal ilişki alt ölçeği ile Serbest Zaman Değerlendirme Anketinin toplam puanı arasında da anlamlı ters bir ilişki bulundu $(p<0,001)$. Tartışma: Bu bulgular ışığında öğrencilerin cep telefonuna bağımlııkları artııça ve kişiler arası sosyal ilişkileri azaldıkça serbest zaman aktivitelerinden yeni bir şeyler öğrenme ile entelektüel uyarıların azaldığı ve onların yorucu akademik yaşantılarında gevşemelerini engellediği görülmektedir.
\end{abstract}

Anahtar Kelimeler: Cep telefonu; Boş zaman aktiviteleri; Eğitim; Rahatlama

\section{ABSTRACT}

Purpose: The aim of this study was to examine the relationship between the use of mobile phones by college students and their leisure time activities satisfaction. Material and Methods: 132 volunteers who participated in the study (average age $20.7 \pm 2.47,47.3 \%$ male) were included in the study. Leisure satisfaction scale and Mobile Phone Problem Use Scale were used in the study. Results: The total score of the mobile phone problem use scale was between the independence and social relation subscale and the education and relaxation subscales of the leisure satisfaction scale $(p<0.001)$ and between the mobile phone problem use questionnaire and the social interaction subscale and the total score of the leisure satisfaction scale $(p<0.001)$. Conclusion: In these findings, it is seen that as the dependence of the students on the mobile phone increases and the social relations between the people decrease, learning something new from the leisure time activities decreases the intellectual stimulus and prevents the relaxation in their exhausting academic life.

Keywords: Mobile phone; Leisure activities; Education; Relaxation 
Türkiye İstatistik Kurumu tarafından yapılan "Hane halkı bilişim teknolojileri kullanımı" araştırmasına göre Türkiye'de teknoloji kullanımının \%77 ile 16-24 yaş grubu olduğu gösterilmiştir. Ayrıca bu araştırmaya göre mobil telefon kullanımı yine bu yaş grubu için \%97'dir (TÜİK, 2016). Çağımızda cep telefonu, artık sadece uzaktan iletişim aracı olarak kullanılmamaktadır. Hatta cep telefonu, internet bağlantısı ve birçok programın kullanılabilirliği ile bir bilgisayarın tüm özelliklerini göstermektedir. Kullanıcılara fotoğraf ve video çekimi, mesajlaşmanın yanı sıra mekân sınırlaması olmadan WEB'de gezinme, çok oyunculu oyunları oynayabilme, video izleme ve sosyal medyay kullanma gibi imkânlar sağlamaktadır. Bu nedenle özellikle yeni neslin hayatının her alanına yerleşen sosyal bir araç olması yadsınamaz. Bugünün üniversite öğrencileri bu teknoloji ile yetiştiği için cep telefonu ile ilgili işlevleri hızla benimsemişlerdir. Bu kullanım sıklığı onların dünya ile etkileşim biçimlerini de değiştirmiştir (Lepp, 2014a). Cep telefonu ile serbest zaman arasındaki ilişkiyi gösteren ilk araştırma 2007 yılında Foley ve arkadaşları tarafından yapılmıştır (Foley, Holzman ve Wearing, 2007). Özellikle ergen bayanlar arasında moda ve bakım ile ilgili kullanımın fazla olduğu bildirilse de işlevsel olarak çalışma ortamında da eğlenceli aktivitelere erişimin olması bir kullanım motivasyonu olarak karşımıza çıkmaktadır (Foley ve ark, 2007). Başka bir araştırma üniversite öğrencilerinin cep telefonlarını internet, video izleme ve oyun oynama ile sosyal paylaşım için kullandığını belirtmiştir (Lepp, 2014b). Ayrıca akıllı telefonların özelliklerinin eğlence amaçıı tasarlandığını gösteren bir çalışma mevcuttur (Lepp, Li, Barkley ve ark, 2015). Ancak araştırımalar cep telefonunun serbest zaman aktivitesi olarak kullanımının hayatı kolaylaştırmadaki olumlu yönlerinin yanı sıra olumsuz yönlerini de ortaya koymaktadır. 2012 de yayınlanan bir çalışmada üniversite öğrencilerinin kullandığı kısa mesajlaşmanın yalnızlık ve kaygı düzeyini artırdığı sonucuna varmıştır (Wang, Park ve Fesenmaier, 2012). Bir başka araştırma cep telefonu kullanımının depresyon ve kaygıyı artırdığı, kişiler Tablo 1. Demografik bilgiler arası etkileşim ile öz güveni azalttığı ve sosyal etkileşimde başarısızlığı artırdığını bildirmiştir $(\mathrm{Ha}$, Chin, Park ve ark, 2008). 2017'de yayınlanmış bir araştırıma da gençlerden cep telefonu kullanma bağımlılı̆ının arttığı ve bu durumun uyku kaliteleri ile davranışlarını olumsuz etkilediği gösterilmiştir (Ruchi-Upadhyay ve Mahendra, 2017). Cep telefonlarının artan kullanımı nedeni ile bu yaş grubunun fiziksel aktivitelerinin olumsuz etkilediğini tespit eden araştırımalar da mevcuttur (Lepp, Barkley, Sanders ve ark, 2013; Barkley, Lepp ve Salehi-Esfahani, 2016). Serbest zaman aktivitelerinin sağlık ve iyilik hali için önemli olduğu ve zihinsel ve fiziksel sağlığın teşvik edilmesinde ve sürdürülmesinde kritik rol oynadığı bilinmektedir (Mannell, 2007). Bu nedenle cep telefonunun hayatımızdaki serbest zamanın büyük kısmını kaplayacak kadar eğlence sunuyor, talep görüyor ve nerede ise bağımlılık yapıyor ise serbest zaman aktivitelerimizden memnuniyetimize etkisi ve bu durumdan nasıl etkilendiği hala belirsizlikler taşıdığı için anlaşılması literatür için önemlidir (Lepp ve ark, 2013). Bu nedenle bu çalışmanın amacı üniversite öğrencilerinin cep telefonu kullanımının serbest zaman aktiviteleri memnuniyeti ile ilişkisini incelemektir.

\section{GEREÇ VE YÖNTEM}

Kesitsel bir çalışmadır. Araştırmanın örneklemini 2017-2018 öğretim yılı güz ve bahar döneminde Hacettepe Üniversitesi Sağlık Bilimleri Fakültesi Ergoterapi Bölümünde okuyan, çalışmaya katılmaya gönüllü olan 132 öğrenci oluşturmaktadır. Çalışmanın etik kurulu; Hacettepe Üniversitesi Senato Etik Komisyonu'ndan çalışmanın yapılmasında etik açıdan sakınca olmadığına ilişkin izin alındı (431-859). Çalışma öncesi tüm katıımcılar çalışma ile ilgili bilgilendirildi ve gönüllü katııı formu imzalatıldı. Öğrenciler veri toplama araçlarını sınıflarında doldurmuşlardır. Öğrencilerin yaş aralığı 18-28'dir. Araştırma kapsamındaki üniversite öğrencilerinin yaş ortalaması $20,7 \pm 2,47$ olup, $\% 47,3$ 'ü erkekti (Tablo 1). Katılımcıların \%100'ü akıllı telefon kullanıcısı idi.

\begin{tabular}{llll}
\hline & & $\mathrm{n}$ & $\%$ \\
\hline Cinsiyet & Erkek & 62 & 47,3 \\
& Kadın & 70 & 62,7 \\
\hline Üniversitedeki yılı & 1 & 22 & 16,6 \\
& 2 & 42 & 31,8 \\
& 3 & 31 & 25,4 \\
& 4 & 37 & 28,0 \\
\hline Toplam & & 132 & 100
\end{tabular}


Akıllı telefonu kullanım alanları \%100 iletişim / telefon / mesajlaşma / mail / sosyal medya, \%93 eğlence/oyun, \%72'si not tutma, hesap yapma ve saat özelliklerini, \%23 moda takibi/alışveriş, \%8'i banka işleri/resmi ve diğer işler ile ilgili kullanıyorduÇalışmamıza dahil etme kriterleri; Hacettepe Üniversitesi Sağlık Bilimleri Fakültesi Ergoterapi Bölümünde 2017-2018 öğretim yılı güz ve bahar döneminde öğrenim görmek, onam formunu imzalamış olmak ve Türk dilini okuyup anlıyor olmaktır.

Çalışmada Serbest Zaman Değerlendirme Anketi ve Cep Telefonu Problemli Kullanım Ölçeği kullanılmıştır.

Serbest Zaman Değerlendirme Anketi: Serbest zamanı ile ilgili kişisel ihtiyaçlarının birey tarafından algısı ve tatminini ölçen aracın 24 maddesi 6 alt ölçeği vardır ve her alt ölçek 4'er maddelidir. Bunlar; psikolojik, eğitim, sosyal, gevşeme, fiziksel ve estetiktir. Bu ölçeğin puanlanması 5'li 'likert' skalası (1; hiçbir zaman-5; her zaman) ile değerlendirilir. Puan arttıkça memnuniyet artar (Beard ve Ragheb, 1980; Gökçe ve Orhan, 2011).

Cep Telefonu Problemli Kullanım Ölçeği: Cep telefonu yanlış kullanımı ve cep telefonunun uzun süreli kullanımına bağlı oluşabilecek olumsuz etkileri ölçmek amacıyla geliştirilen ölçek bağımlılık (9 soru), sosyal ilişkiler (7 soru), sonuçlar (10 soru) olmak üzere üç alt bölümden oluşmaktadır. Her bir madde 0-4 puan ( $0=$ kesinlikle katılmıyorum/hiç, $4=$ kesinlikle katılıyorum/çok sık) aracılığı ile puanlanmaktadır.
Toplam puanın yüksek olması, kişinin cep telefonunu problemli kullandığını göstermektedir (Augner ve Hacker, 2012; Tekin, Güneş ve Çolak, 2014).

\section{Istatistiksel Analiz}

Ölçeklerin alt parametreleri arasındaki ilişki Spearman korelasyon analizi ile incelenmiştir. Anlamlılık düzeyi 0,05 olarak kabul edilmiştir.

\section{SONUÇLAR}

Cep telefonu problemli kullanım ölçeğinin toplam puanı, bağımsızlık ve sosyal ilişki alt ölçeği ile serbest zaman değerlendirme anketinin eğitim ve gevşeme alt ölçekleri arasında (txe $r=-0,34, p<0,001$; txg $r=-0,30, p=0,001$; bxe $r=-0,29, p=0,001$;bxg $r=-$ $0,16, p=0,041$; sxe $r=-0,34, p<0,001$; sxg $r=-0,30$, $p=0,001)$ ve cep telefonu problemli kullanım ölçeğinin sosyal ilişki alt ölçeği ile serbest zaman değerlendirme anketinin toplam puanı arasında da ters bir ilişki bulunmuştur ( $r=-0,23 ; p=0,008)$ (Tablo 2). Cep telefonunun yanlış kullanımı, bağımlılığı, sosyal ilişkileri engellemesi ile serbest zaman aktivitelerinin eğitim ile gevşeme sağlaması arasında negatif yönde anlamlı ilişki tespit edilmiştir. Bu bulgular ışığında öğrencilerin cep telefonuna bağımlılıkları arttıkça ve kişiler arası sosyal ilişkileri azaldıkça serbest zaman aktivitelerinden yeni bir şeyler öğrenme ile entelektüel uyarıların azaldığı ve onların yorucu akademik yaşantılarında gevşemelerini engellediği yani stres ile gerginliğin arttığı görülmektedir.

Tablo 2. Korelasyon sonuçları

\begin{tabular}{llll}
\hline & Toplam & Bağımsızlık & Sosyal ilişki \\
\hline Eğitim & $0,34^{* *}$ & $-0,29^{* *}$ & $-0,34^{* *}$ \\
\hline Gevşeme & $0,30^{* *}$ & $-0,16^{* *}$ & $-0,30^{* *}$ \\
\hline SZDA top & & & $-0,23^{* *}$
\end{tabular}




\section{TARTIŞMA}

Önceki cep telefonu kullanımı ile ilgili davranış araştırmaları bağımlı cep telefonu kullanıcılarına odaklanmaktaydı (Beranuy, Oberst, Carbonell ve ark, 2009; Takao, Takahashi ve Kitamura, 2009; Bianchi ve Phillips, 2005; Sánchez-Martínez ve Otero, 2009; Jenaro, Flores, Gómez-Vela ve ark, 2007). Bu nedenle cep telefonuna problemli kullanımı olmayan gençlerin serbest zaman memnuniyetine etkisi bilinmiyordu. Bu çalışma, sıradan cep telefon kullanan üniversite öğrencilerinin cep telefonu kullanımları ile serbest zaman aktiviteleri memnuniyeti arasındaki ilişkiyi göstermektedir. Araştırmanın sonucuna göre üniversite öğrencilerinin cep telefonunun problemli kullanımı ile serbest zaman memnuniyetleri arasında negatif yönde anlamlı bir ilişki bulundu.

Öncelikle, Türkiye istatistik kurumunun verilerine göre ülkemizde cep telefonu abone sayısı 74 milyon; internet abone sayısı 49 milyonu bulmuştur (TÜiK, 2016). Ayrıca telefon bağımlılığına yönelik bir araştırmada 18 yaş üstü cep telefonu kullanıcılarının $\% 52$ 'si telefonlarını 5-10 dk. aralıklarla kontrol etmektedirler. Ayrıca \%37'si yemek esnasında; \%32'si önemli bir görüşmede bile telefonlarını kullandıklarını belirtmiştir (Kuyucu, 2017). Janković ve arkadaşları (2016), akıllı telefon kullanımının serbest zaman aktivitelerinin etkisini gösteren araştırmasında özellikle gençlerin günlük yaşamdaki aktivitelerini akıllı telefonları aracılığı ile sunmalarına ve beğeni ile yorumlara kavuşmalarına sebep olduğunu hatta gençlerin "aktivitelerimi sunmazsam ne anlamı olur?" şeklinde söylemlerine dikkat çekmektedir. Bu bireylerin ödüllendirilmek için aktiviteye bağladığının bir göstergesi olabilir. Ayrıca cep telefonunun aşıı kullanımının yani telefon ile geçirilen uzun zamanın bireyleri fiziksel aktivitelerden uzaklaştırdığını yani bizim sonuçlarımızla tutarlı olarak serbest zaman aktivitelerinin olumsuz etkilendiğini göstermiştir (Janković, Nikolić, Vukonjanski ve ark, 2016).

$\mathrm{Bu}$ araştırmanın önemli bir bulgusu serbest zaman memnuniyet anketi sonuçlarına göre cep telefonu bağımlıı̆̆ artıkça "gevşeme" alt parametresinde azalma olduğu yani kişilerin genelde kendilerini gergin hissettikleri görülmüştür. Lepp ve arkadaşları 2013'te yaptıkları çalışmada cep telefonu kullanım süresinin artması ile kardiyorespiratuar zindeliğin negatif ilişkili olduğunu ve daha az fiziksel uygunluklarının olduğu sonucunu bulmuşlardır (Lepp ve ark, 2013). Ayrıca, bir başka çalışma problemli cep telefonu kullanımının sedanter yaşam tarzı ile ilişkisini göstermiştir (Barkley ve ark, 2016; Leena, Tomi ve Arja, 2005). Yine literatüre göre sedanter yaşam tarzını benimsemiş bireylerin düşük fiziksel uygunlukları onların gevşeme ve rahatlamalarını olumsuz yönde etkilemektedir (Lowry, Wechsler, Galuska ve ark, 2002). Bu durum çalışmamızda da anlamlı olarak ilişkilendirilmiştir. Cep telefonunun problemli kullanımının bireyin gevşemesini engelleyen bir serbest zaman aktivitesi olduğu sonucuna varılmıştır.

Literatür sosyalleşmenin tüm serbest zaman aktivitelerinde olduğu gibi cep telefonu kullanımının da baskın bir özelliği olduğunu ve herhangi bir sebepten bir araya gelen gençler yaptıkları her aktiviteyi her firsatta ve her ortamda cep telefonu yolu ile paylaştıklarını belirtmektedir. Ancak son yıllarda yayınlanan çalışmalarda bu durumun yanı sıra kendilerini dinlendirmek, yalnız zamanlarını daha eğlenceli hale getirmek, daha az eforlu serbest zaman firsatı yaratmak gibi sebeplerin de yaygınlaştığı belirtilmektedir (Kaya ve Argan, 2015). Ayrıca cep telefonu kullanım frekansının artmasının yalnızlaştırdığı ve sosyal ilişkileri olumsuz yönde etkilediği literatürde gösterilmiştir (Kim, 2018). Cep telefonunun problemli kullanımının sosyal ilişkileri azaltması sonucu yine bireyin gevşeyememesi ile ilişkili bulunmuştur. Dahası stabil sosyal gruplar, uzun soluklu sosyal ilişkileri geliştirir ve bu dinamik sosyal süreç hayata bakışımızı anlamlı hale getirir. Yapılandırılmış sosyal ortam sosyal öğrenme için en iyi zemindir (Coussi-Korbel ve Fragaszy, 1995). Ancak sosyal ortamı yerine cep telefonunu tercih eden gencin öğrenme süreçlerinin de olumsuz etkilendiğini çalışmamız göstermektedir.

Her ne kadar cep telefonu elimizin altındaki bilgi hazinesi de olsa bağımlıık derecesinde kullanım yeni şeyler öğrenmeyi engellemektedir. İkinci olarak bağımlılık arttıkça serbest zaman aktiviteleri sırasında yeni şeyler öğrenmesine ket vurmaktadır.

Çalışmamızın bazı limitasyonları mevcuttur. Üniversite öğrencilerinde cep telefonu kullanımının serbest zaman aktiviteleri memnuniyetine etkisini inceleyen çalışmamız da cep telefonunun problemli kullanımının akademik başarıya etkisinin (Lepp, Barkley ve Karpinski, 2014) ve cep telefonunun problemli kullanımının cinsiyetler arası değişkenlik gösterip göstermediğinin incelenmemesi bu araştırmanın limitasyonları olarak sıralanabilir.

Cep telefonu kullanımının üniversite gençlerinin zihinsel ve fiziksel sağlık ve refahın sürdürülmesinde önemli bir yere sahip serbest zaman aktivitelerine etkisinin ilerleyen zamanlarda artarak devam edeceğini, bu nedenle üniversitelerin şimdiden bu 
olumsuzlukları en aza indirmek için, onların serbest zamanlarının yeniden yapılandırılması ile ilgili üniversite yönetimlerinin önlem almasının önemli olduğu düşünülmektedir. Ayrıca ergoterapistler tarafından bu öğrencilerin aktivite dengesi açısından değerlendirilerek yaşam tarzı değişikliği ve orta veya hafif düzeyde fiziksel serbest zaman aktivitelerine yönlendirilmesi önemlidir.

\section{Kaynaklar}

Augner, C., \& Hacker, G. W. (2012). Associations between problematic mobile phone use and psychological parameters in young adults. International Journal of Public Health, 57(2), 437-441.

Barkley, J. E., Lepp, A., \& Salehi-Esfahani, S. (2016). College students' mobile telephone use is positively associated with sedentary behavior. Am J Lifestyle Med, 10(6), 437441.

Beard, J. G., \& Ragheb, M. G. (1980). Measuring leisure satisfaction. J Leis Res, 12(1), 20.

Beranuy, M., Oberst, U., Carbonell, X., \& Chamarro, A. (2009). Problematic Internet and mobile phone use and clinical symptoms in college students: The role of emotional intelligence. Comput Human Behav, 25(5), 1182-1187.

Bianchi, A., \& Phillips, J. G. (2005). Psychological predictors of problem mobile phone use. Cyberpsychol Behav, 8(1), 39-51.

Coussi-Korbel, S., \& Fragaszy, D. M. (1995). On the relation between social dynamics and social learning. Animal Behaviour, 50(6), 1441-1453.

Foley, C., Holzman, C., \& Wearing, S. (2007). Moving beyond conspicuous leisure consumption: Adolescent women, mobile phones and public space. Leisure Studies, 26(2), 179-192.

Gökçe, H., \& Orhan, K. (2011). Serbest zaman doyum ölçeğinin Türkçe geçerlilik güvenirlik çalışması. Spor Bilimleri Dergisi, 22(4), 139-145.

Ha, J. H., Chin, B., Park, D. H., Ryu, S. H., \& Yu, J. (2008). Characteristics of excessive cellular phone use in Korean adolescents. Cyberpsychol Behav, 11(6), 783-784.

Janković, B., Nikolić, M., Vukonjanski, J., \& Terek, E. (2016). The impact of Facebook and smart phone usage on the leisure activities and college adjustment of students in Serbia. Comput Human Behav, 55, 354-363.

Jenaro, C., Flores, N., Gómez-Vela, M., González-Gil, F., \& Caballo, C. (2007). Problematic internet and cell-phone use: Psychological, behavioral, and health correlates. Addiction research \& theory, 15(3), 309-320.

Kaya, S., \& Argan, M. (2015). An Exploratory Qualitative Study on Mobile Leisure (M-Leisure): A Case of Mobile Phone Users in Turkey. Journal of Internet Applications \& Management/Internet Uygulamaları ve Yönetimi Dergisi, $6(1)$.
Kim, J. H. (2018). Psychological issues and problematic use of smartphone: ADHD's moderating role in the associations among loneliness, need for social assurance, need for immediate connection, and problematic use of smartphone. Comput Human Behav, 80, 390-398.

Kuyucu, M. (2017). Gençlerde akıllı telefon kullanımı ve akıllı telefon bağımlıı̆ı sorunsalı: "akıllı telefon (kolik)" üniversite gençliği. Global Media Journal TR Edition, 7(14), 328-359.

Leena, K., Tomi, L., \& Arja, R. (2005). Intensity of mobile phone use and health compromising behaviors-how is information and communication technology connected to health-related lifestyle in adolescence?. Journal of Adolescence, 28(1), 35-47.

Lepp, A. (2014a). Exploring the relationship between cell phone use and leisure: an empirical analysis and implications for management. Managing Leisure, 19(6), 381-389.

Lepp, A. (2014b). The intersection of cell phone use and leisure: A call for research. J Leis Res, 46(2), 218-225.

Lepp, A., Barkley, J. E., \& Karpinski, A. C. (2014). The relationship between cell phone use, academic performance, anxiety, and satisfaction with life in college students. Comput Human Behav, 31, 343-350.

Lepp, A., Barkley, J. E., Sanders, G. J., Rebold, M., \& Gates, P. (2013). The relationship between cell phone use, physical and sedentary activity, and cardiorespiratory fitness in a sample of US college students. Int J Behav Nutr Phys Act, 10(1), 79.

Lepp, A., Li, J., Barkley, J. E., \& Salehi-Esfahani, S. (2015). Exploring the relationships between college students' cell phone use, personality and leisure. Comput Human Behav, 43, 210-219.

Lowry, R., Wechsler, H., Galuska, D. A., Fulton, J. E., \& Kann, L. (2002). Television viewing and its associations with overweight, sedentary lifestyle, and insufficient consumption of fruits and vegetables among US high school students: differences by race, ethnicity, and gender. J Sch Health, 72(10), 413-421.

Mannell, R. C. (2007). Leisure, health and well-being. World Leis J, 49(3), 114-128.

Sánchez-Martínez, M., \& Otero, A. (2009). Factors associated with cell phone use in adolescents in the community of Madrid (Spain). CyberPsychology \& Behavior, 12(2), 131137.

Takao, M., Takahashi, S., \& Kitamura, M. (2009). Addictive personality and problematic mobile phone use. CyberPsychology \& Behavior, 12(5), 501-507.

Tekin, C., Güneş, G., \& Colak, C. (2014). Adaptation of Problematic Mobile Phone Use Scale to Turkish: A Validity and Reliability Study [Cep Telefonu Problemli Kullanım (Pu) Ölçeğinin Türkçe'ye Uyarlanması: Geçerlik Ve Güvenilirlik Çalışması]. Medicine Science, 3(3). 
Türkiye İstatistik Kurumu. (2016). Hanehalkı Bilişim Teknolojileri Kullanım Araştırması. http://www.tuik.gov.tr/PreTablo.do?alt_id=1028, Erişim tarihi: 02.01.2018

Wang, D., Park, S., \& Fesenmaier, D. R. (2012). The role of smartphones in mediating the touristic experience. J Travel Res, 51(4), 371-387. 